\title{
Acidentes de trabalho: violência urbana e morte em Porto Alegre, Rio Grande do Sul, Brasil 1
}

\author{
Work-related accidents: urban violence and death \\ in Porto Alegre, Rio Grande do Sul, Brazil 1
}

Paulo Antonio Barros Oliveira 2

Jussara Maria Mendes 3

\footnotetext{
1 Trabalho financiado pela Fapergs (Processo 93.0369-2) 2 Centro de Documentação, Pesquisa e Formação em Saúde e Trabalho, Departamento de Medicina Social, Faculdade de Medicina, Universidade Federal do Rio Grande do Sul. Rua Ramiro Barcelos 2600, sala 413, Porto Alegre, RS 90035-003, Brasil. 3 Departamento de Prática em Serviço Social, Pontifícia Universidade Católica do Rio Grande do Sul. Av. Ipiranga 6681, prédio 15, 3 o andar, Porto Alegre, RS.
}

\begin{abstract}
This article focuses on the magnitude of work-related deaths in Porto Alegre, the capital of Rio Grande do Sul State, Brazil. Death certificates were used to investigate 159 cases, or $18 \%$ of the 877 deaths from external causes in 1992. Some 31 cases were identified. The principal cause of death among these workers was homicide, with 58\% of cases (15 from fire arms and 3 from knives), followed by traffic accidents, with 29\% (5 motor vehicle collisions and 4 pedestrians run down by motor vehicles). Of these 31 deaths, 17 were workers from the formal labor market, of whom 11 did not fit into the regular reporting procedures for work-related accidents. The other 14 deaths were of workers from the informal labor market (7), individuals involved in illicit activities (6), and unknown (1), in which cases reporting as work-related accidents was also inappropriate. These data suggest negligence by the public sector in dealing with this issue and the fact that official statistics fail to reflect the reality of daily working conditions. The authors conclude that health surveillance requires other data collection mechanisms besides those used by the Social Welfare System, so as to include all actual risks related to work situations.
\end{abstract}

Key words Occupational Accidents; Worker's Health; Occupational Mortality; Violence

Resumo O presente estudo identifica a magnitude dos óbitos relacionados com o trabalho entre os residentes de Porto Alegre. A partir das Declarações de óbito, e utilizando metodologia qualitativa, confirmando a causa das mortes através de inquérito familiar, foram investigados 159 óbitos, 18\% dos 877 classificados como devidos a Causas externas ocorridos em 1992. Foram identificados 31 casos. As principais causas dos óbitos entre estes trabalhadores foram homicídio, em 58\% dos casos (15 com arma de fogo e 3 com arma branca), seguido de acidente de trânsito, em 29\% (5 colisões e 4 atropelamentos). Dos 31 óbitos, 17 foram de trabalhadores do mercado formal de trabalho e, dentre estes, 11 não se enquadram nas normas de notificação acidentária. Outros 14 óbitos foram de trabalhadores ligados: ao mercado informal de trabalho (7), à execução de atividades ilícitas (6) e à atividade ignorada (1), os quais também não são notificáveis. Isto desvela a omissão do Estado no tratamento desta questão e o quanto os dados oficiais não traduzem a realidade existente no cotidiano do trabalho. Os autores concluem que, para fins de Vigilância em Saúde, faz-se necessária a utilização de outros mecanismos de coleta de dados, além dos utilizados pela Previdência Social, de modo a incluir todas as situações reais de risco à saúde provenientes do trabalho.

Palavras-chave Acidentes do Trabalho; Trabalho; Saúde do Trabalhador; Mortalidade Ocupacional; Violência 


\section{Introdução}

Realizamos a presente pesquisa com o propósito de ampliar os conhecimentos sobre a subnotificação dos acidentes de trabalho com morte, e avaliar as declarações de óbito (DO) como instrumento de registro dos óbitos relacionados ao trabalho.

Inicialmente serão apresentados os dados relacionados à mortalidade e ao óbito pelo trabalho. Os fenômenos de seu sub-registro e de sua subnotificação são conhecidos. Como observam Laurenti \& Mello Jorge (1993), as estatísticas de mortalidade constituem instrumento de grande valor em epidemiologia, demografia e administração sanitária, todavia nem sempre são fidedignas, principalmente no que diz respeito à causa de morte. Mesmo assim, os estudos sobre mortalidade são valorizados em todo o mundo, porque, dentre os diversos índices e coeficientes de uso em saúde, os que neles se apresentam estão entre os que conseguem maior consenso internacional e maior congruência dos métodos de diagnóstico e de coleta de dados nas mais diferentes culturas e nos mais diversos países. Afora isso, como nota Loureiro (1990), "estudos têm demonstrado que a mortalidade por causas externas está associada, através de coeficientes de correlação positivos, a uma série de indicadores sociais como taxa de analfabetismo, taxa de mortalidade e percentual da População Economicamente Ativa (PEA) com rendimento mensal inferior a um salário mínimo. Estas conclusões são mais acentuadas para mortes por homicídio e outras violências".

Em São Paulo, em estudo de 1964, foram encontrados apenas 67,6\% das Declarações de óbito (DO) preenchidos corretamente. Repetido o estudo 10 anos depois, os mesmos erros continuavam a existir (Laurenti \& Mello Jorge, 1993). O Ministério da Saúde realizou campanha nacional para tentar melhorar este quadro preocupante (MS, 1985). Em Porto Alegre, em 1989, rigorosa investigação reclassificou para o Grupo XVI - causas mal definidas - aproximadamente 500 D.O.'s, após ter sido detectada fraude no preenchimento das mesmas.

De um modo geral, nos últimos 15 anos houve aumento da mortalidade por causas externas em quase todas as capitais estaduais do Brasil, comparando-se os coeficientes específicos desde 1980 (Rouquayrol et al., 1993).

Tanto quanto em Porto Alegre, no Estado do Rio Grande do Sul como um todo as causas externas situam-se como a 4 a causa de mortes, antecedida por doenças do aparelho circulatório, neoplasia e doenças do aparelho respirató- rio. Segundo a Fundação Nacional de Saúde (1994), no que se refere à capital federal e às capitais estaduais com mais de um milhão de habitantes, em Brasília, São Paulo, Rio de Janeiro, Recife e Salvador as causas externas são a $2 \underline{a}$ causa geral de morte, em Curitiba, Belém e Fortaleza são a 3ạ, e em Belo Horizonte são a 4a causa de morte. Porém, em Porto Alegre, entre a população de 10 a 50 anos, elas foram a principal causa de morte no ano de 1992 (NIS, 1995a). Porto Alegre situa-se em 7o lugar na mortalidade proporcional por causas externas, precedida por Brasília, São Paulo, Rio de Janeiro, Curitiba, Recife e Salvador. Ainda segundo a mesma fonte, os coeficientes de mortalidade por causas externas destas capitais estaduais situam Porto Alegre em 50 lugar, abaixo do Rio de Janeiro, Recife, São Paulo e Curitiba. A proporção de mortes por causas externas em relação às demais causas é, em Porto Alegre, de $11,8 \%$ (inferior à proporção nacional, de $12,5 \%$ ) e o coeficiente de mortalidade por causas externas por 100.000 habitantes é de 86,5, superior ao do país, que é de 72,9 (NIS, 1995b).

No Rio Grande do Sul, desde a década de 80, as causas externas têm diminuído como causa geral de morte, assim como as causas mal definidas, infecto-parasitárias e perinatais. No entanto têm aumentado os neoplasmas, as doenças dos aparelhos respiratório e digestivo e as endócrino-imunitárias. Permanecem estabilizados os casos de doenças do aparelho circulatório. Entre as cidades do Estado com mais de 200.000 habitantes, as causas externas situam-se como 4 a causa de morte em Canoas $(12,0 \%)$ e Pelotas $(7,3 \%)$, como $3 \underline{a}$ causa em Novo Hamburgo (15,5\%) e Caxias do Sul $(13,5 \%)$, e como $5 \underline{a}$ causa em Santa Maria $(8,2 \%)$. Os coeficientes de mortalidade por causas externas por 100.000 habitantes que explicitam melhor o risco ou a probabilidade de se morrer por alguma causa violenta, foram de 63,9 em Porto Alegre, situando-a em 4o lugar, após Novo Hamburgo $(95,1)$, Canoas $(79,8)$ e Caxias do Sul $(78,1)$, e antes de Pelotas $(60,3)$ e Santa Maria $(56,7)$ (NIS, 1995b).

No Estado do Rio Grande do Sul, assim como no Brasil como um todo e nos demais países das Américas, a mortalidade por causas externas distribui-se aproximadamente em uma relação de 3/ 1 entre homens e mulheres. Comparando-se Porto Alegre à Colômbia, os comportamentos são diferentes (2/1 e 6/1, respectivamente) (OMS, 1985; Organización Panamericana de la Salud, 1994; NIS, 1995b). Especificamente no caso colombiano, o coeficiente de mortalidade masculina por causas externas é de aproximadamente o dobro daqueles dos de- 
mais países das Américas. Estes dados nos colocam a questão da relação direta entre a morte por causas externas e a violência na sociedade, bem como a da associação da morte violenta com o gênero masculino.

Se no que se refere à mortalidade, a fidedignidade dos dados notificados tem sido um problema, em relação aos acidentes de trabalho a subnotificação é ainda maior. Estudos em Porto Alegre têm identificado uma subnotificação de aproximadamente $10 \%$ nos ramos hospitalar e metalúrgico (Antoniazzi, 1992; Marques, 1993). Isto evidencia a necessidade de se estudar melhor esta categoria de eventos, responsável, nas últimas duas décadas, por mais de 28 milhões de acidentes e mais de 90.000 mortes (Alves \& Luchesi, 1992).

A redução na notificação dos casos de AT a partir da década de 70 tem sido relacionada às modificações nos critérios de enquadramento dos casos, as alterações nos aspectos legais havendo contribuído para a modificação da série histórica dos dados epidemiológicos (Rego, 1993; Possas, 1981; Ribeiro \& Lacaz, 1984). Rego chama a atenção para a diminuição do número de acidentes de trabalho e o concomitante aumento da taxa de letalidade por acidente de trabalho a partir de 1976, ano da reforma da legislação que tornou responsabilidade das empresas o pagamento pelo afastamento do trabalho nos primeiros 15 dias após o acidente. A taxa de letalidade por acidente de trabalho cresceu aproximadamente $1.300 \%$ em 23 anos, apesar de não ser observada mudança importante no número absoluto de óbitos.
Beraldo et al. (1993) analisaram 7.769.138 de óbitos notificados em dez anos (1979-1988) e encontraram 813.558 classificados como causas externas, dentre os quais 26.612 foram enquadrados como acidentes de trabalho (Tabela 1). Estes números significam que 3,3\% do total de óbitos notificados deviam-se a causas externas e $0,3 \%$ a acidentes de trabalho. No mesmo período a Previdência Social, através da Comunicação de Acidente do Trabalho (CAT), foi notificada de 46.839 óbitos por acidentes de trabalho. A notificação do sistema de saúde mostrou-se menos fidedigna e correspondeu a apenas $56,8 \%$ dos casos notificados à Previdência Social.

\section{Material e método}

Através de uma investigação prospectiva, com amostra sistemática, conforme os óbitos aconteciam, foram analisados óbitos decorrentes de causas externas ocorridos de abril de 1992 a março de 1993 entre residentes de Porto Alegre/RS. Foram admitidas na amostra todas as Declarações de óbito (DO) referentes a mortes com causa básica enquadrada como causa externa. Foi utilizado o mesmo critério da Organização Mundial de Saúde (1985, apud Laurenti \& Mello Jorge, 1993), para a classificação dos óbitos por causa externa, ou seja, "a morte de causa não natural que sobreveio em decorrência de um acidente ou qualquer tipo de violência". Como causa básica de morte foi considerada quer a doença ou lesão que iniciou a sucessão

Tabela 1

Freqüências absolutas e relativas dos óbitos por acidente do trabalho, confrontados com todos os óbitos, com as causas externas e com os óbitos notificados pela CAT* Brasil, 1979-1988.

\begin{tabular}{|c|c|c|c|c|c|c|c|c|}
\hline & \multicolumn{2}{|c|}{ Acidente de Trabalho } & \multicolumn{2}{|c|}{ Total de DOs** } & \multicolumn{2}{|c|}{ Causas Externas } & \multicolumn{2}{|c|}{ CAT } \\
\hline & $n$ & $\%$ & $n$ & $\%$ & $n$ & $\%$ & $n$ & $\%$ \\
\hline 1979 & 2732 & 10,3 & 711742 & 0,4 & 65253 & 4,2 & 4673 & 58,5 \\
\hline 1980 & 2758 & 10,4 & 750727 & 0,4 & 70212 & 3,9 & 4824 & 57,7 \\
\hline 1981 & 2565 & 9,6 & 750276 & 0,3 & 71833 & 3,6 & 4808 & 53,3 \\
\hline 1982 & 2425 & 9,1 & 741614 & 0,3 & 73460 & 3,3 & 4496 & 53,9 \\
\hline 1983 & 2119 & 8,0 & 771203 & 0,3 & 78008 & 2,7 & 4214 & 50,3 \\
\hline 1984 & 2218 & 8,3 & 809825 & 0,3 & 82386 & 2,7 & 4508 & 49,2 \\
\hline 1985 & 2681 & 10,1 & 788231 & 0,3 & 85845 & 3,1 & 4384 & 61,2 \\
\hline 1986 & 3004 & 11,3 & 811565 & 0,4 & 95968 & 3,1 & 4578 & 65,6 \\
\hline 1987 & 3260 & 12,3 & 799621 & 0,4 & 94421 & 3,5 & 5738 & 56,8 \\
\hline 1988 & 2850 & 10,7 & 834334 & 0,3 & 96172 & 3,0 & 4616 & 61,7 \\
\hline Total & 26612 & 100,0 & 7769138 & 0,3 & 813558 & 3,3 & 46839 & 56,8 \\
\hline
\end{tabular}

Fonte: Beraldo et al., 1993.

* CAT - Denominação usual do documento com o qual é efetivada a Comunicação de Acidentes do Trabalho.

** DOs - Declarações de óbito. 
de eventos mórbidos que levou diretamente à morte, quer a(s) circunstância(s) do acidente ou violência que produziu a lesão fatal.

A amostra foi definida como todos os casos ocorridos dentro de uma semana a cada quatro semanas epidemiológicas. O tamanho da amostra foi assim determinado pelo processo de escolha das D. O.'s que compuseram a pesquisa. Estas foram fornecidas pela Secretaria de Saúde e Meio Ambiente do Estado do Rio Grande do Sul (SSMA/RS), após revisão técnica e classificação realizadas por seu Núcleo de Informação em Saúde. O início do processo de investigação deu-se a partir do sorteio de uma semana entre as quatro semanas epidemiológicas do primeiro mês de levantamento dos dados. A partir daí, foi escolhida a quarta semana, e o processo repetiu-se subseqüentemente. As informações das Declarações de óbito foram cotejadas com outras colhidas junto ao Instituto de Medicina Legal, onde são realizadas as necropsias de todos os óbitos por causas externas, e ainda junto aos cemitérios e funerárias.

Para determinar os casos a serem incluídos na pesquisa, considerou-se como processo de trabalho a atividade humana que transforma. a natureza com fim econômico (Carvalho et al., 1977; Albornoz, 1994). Procurou-se identificar claramente que o fruto econômico desta atividade exercida pela pessoa no momento do óbito era dirigida para a sua própria subsistência ou a dos membros da família, não sendo classificável como diversão, hobby ou lazer. Convencionou-se também incluir o trabalho doméstico, tanto masculino como feminino, mesmo quando o acidente ocorresse na própria residência da vítima, além dos casos em que desse no trajeto da residência e do local de refeição para o local de trabalho e vice-versa.

Para validação qualitativa das informações, e em um processo de triangulação, foi utilizada a técnica da Necropsia Verbal. Esta consiste de visitas domiciliares e entrevistas semi-estruturadas com familiares, amigos ou testemunhas de todos os casos investigados. A partir desta história contada e dos demais dados coletados reconstitui-se a história da ocorrência, o diagnóstico da causa da morte e outras informações consideradas relevantes (Benguigui, 1986; Bendt, 1989; Litman, 1989; Chandramohan et al., 1994). O grupo de pesquisadores apoiou-se em experiência prévia do Programa de Controle da Doença Respiratória Aguda em Crianças, da Secretaria Estadual de Saúde, que utilizou a mesma metodologia no diagnóstico de óbitos e na avaliação dos serviços (Chatkin et al., 1990).
Para fins desta pesquisa foram consideradas atividades ilícitas aquelas que preencheram pelo menos duas condições: classificável como ilícito ou contravenção penal, e era informado que auxiliava no sustento do indivíduo e/ou da família.

\section{Resultados e discussão}

Na testagem do instrumento foram identificados problemas relacionados ao período de realização da entrevista e ao tempo decorrido desde o óbito. Nos primeiros 14 ou 21 dias havia resistência dos familiares em colaborar, pois o choque da perda estava muito presente. Ampliado o intervalo entre óbito e entrevista (120 a 150 dias), aumentava o desencontro com a família no endereço indicado. Isto definiu o período entre o 45ํ e o 90 dia após o óbito como o momento ideal para a realização da entrevista.

A dificuldade inicial para identificar o tempo ideal de coleta dos dados junto às famílias foi relacionada ao fato de que, em um curto espaço de tempo, o núcleo familiar se desestruturava. O óbito do homem, importante fonte da renda, levava à falência do grupo familiar e sua subseqüente desestruturação. Na impossibilidade de manter a moradia, a mulher e os filhos deslocavam-se para outros espaços urbanos, na própria cidade, ou retornavam à cidade de origem, geralmente no interior do estado. A vizinhança informava que tinham mudado para a casa de algum parente.

Dos 183 óbitos ocorridos nas semanas investigadas, 8 casos não foram incluídos na amostra: em 7 casos, embora o óbito tenha ocorrido em Porto Alegre, o local de residência era outro município da região metropolitana (5 casos), outro estado da federação (1), outro país (1); em um caso não se confirmou a causa externa como registrada na D.O.

Dos 175 casos elegíveis, foram investigados 159. As 16 perdas $(9,14 \%)$ foram constituídas por 3 óbitos de pessoas não identificadas, 12 óbitos em que o endereço de familiares, conhecidos ou testemunhas da ocorrência não foi localizado (dados incompletos nos endereços da Declaração de óbito, do Cemitério e do Instituto de Medicina Legal, ou mudança de residência dos familiares), e um único caso de recusa de participação da família, casualmente o óbito da mãe de um médico. Os 175 casos que compuseram a amostra e os 159 investigados representam, respectivamente, $20,06 \%$ e $18,12 \%$ do total dos 877 óbitos ocorridos por causas externas no período investigado. 
$\mathrm{Na}$ amostra geral de 159 casos investigados, as principais causas de óbitos por causas externas encontradas foram homicídio - 40\% (31\% por arma de fogo e $9 \%$ por arma branca) - e acidente de trânsito - 38\% (21\% colisão e $17 \%$ atropelamento). Esses óbitos ocorreram mais freqüentemente em uma população masculina (77\%). Destes, $55 \%$ eram trabalhadores, $48 \%$ eram solteiros e $75 \%$ tinham menos de 40 anos. A escolaridade encontrada foi baixa $(26 \% \mathrm{com}$ o 1o grau escolar completo ou mais). Dos que trabalhavam, $40 \%$ tinham vínculo formal de emprego, 85\% recebiam até dois salários míni- mos e $57 \%$ tinham uma jornada semanal de trabalho superior às 44 horas permitidas pela Constituição Federal. No período da investigação o salário mínimo mensal equivalia a aproximadamente 65 dólares americanos. Beraldo et al. (1993) identificaram que $61,5 \%$ dos trabalhadores que morrem em conseqüência de acidente de trabalho têm até o grau fundamental de escolaridade (até a 4 a série do lo grau) e $7,8 \%$ não têm instrução.

Segundo as informações coletadas, 31 casos foram relacionados com o trabalho (Tabela 2). Em apenas uma terça parte destes casos os fa-

Tabela 2

Óbitos relacionados com o trabalho, segundo a idade, a atividade exercida, classificação do acidente e a causa da morte, Porto Alegre, 1992

\begin{tabular}{|c|c|c|c|c|c|c|}
\hline n & $\begin{array}{l}\text { n do } \\
\text { caso }\end{array}$ & $\begin{array}{l}\text { idade } \\
\text { em anos }\end{array}$ & atividade exercida & $\begin{array}{l}\text { classificação } \\
\text { do acidente }\end{array}$ & causa do óbito & observações \\
\hline 1 & 4 & 31 & motorista de táxi & típico & $\begin{array}{l}\text { assalto seguido de morte - } \\
\text { arma de fogo }\end{array}$ & "queima de arquivo" (?) \\
\hline 2 & 20 & 29 & servente & trajeto & homicídio - arma de fogo & $\begin{array}{l}\text { retornando do trabalho, cobrança } \\
\text { de empréstimo por colegas }\end{array}$ \\
\hline 3 & 34 & 49 & motorista de táxi & típico & $\begin{array}{l}\text { assalto seguido de morte - } \\
\text { arma de fogo }\end{array}$ & proprietário do táxi \\
\hline 4 & 36 & 30 & carpinteiro & típico & choque elétrico seguido de queda & trabalhava na construção \\
\hline 5 & 37 & 50 & representante comercial & trajeto & $\begin{array}{l}\text { assalto seguido de morte - } \\
\text { carbonização }\end{array}$ & indo para o trabalho \\
\hline 6 & 39 & 37 & serralheiro & trajeto & homicídio - arma de fogo & indo para o trabalho \\
\hline 7 & 48 & 29 & corretor de imóveis & trajeto & atropelamento & retornando do trabalho \\
\hline 8 & 53 & 30 & gari - municipal & trajeto & homicídio - arma branca & indo para o trabalho \\
\hline 9 & 75 & 26 & receptação & outros & homicídio - arma branca & na rua, à noite \\
\hline 10 & 78 & 34 & mecânico & outros & homicídio - arma branca & briga, cobrança de serviço prestado \\
\hline 11 & 82 & 21 & militar federal & típico & acidente com arma de fogo & preparava campo de tiro \\
\hline 12 & 90 & 38 & pipoqueiro & trajeto & atropelamento & indo para o trabalho \\
\hline 13 & 93 & 48 & pedreiro & trajeto & colisão & indo para o trabalho \\
\hline 14 & 95 & 40 & pedreiro & trajeto & homicídio - arma branca & indo para o trabalho \\
\hline 15 & 96 & 38 & pedreiro & típico & esmagamento por máquina & rebocava uma parede \\
\hline 16 & 98 & 26 & ignorada & trajeto & colisão & retornando do trabalho \\
\hline 17 & 102 & 38 & pedreiro & trajeto & atropelamento & retornando do trabalho \\
\hline 18 & 103 & 36 & policial civil & outros & homicídio - arma de fogo & executado por gangue \\
\hline 19 & 105 & 15 & balconista & trajeto & afogamento & retornando do trabalho \\
\hline 20 & 113 & 84 & traficante & típico & homicídio - arma de fogo & briga entre gangues \\
\hline 21 & 114 & 38 & motorista & típico & atropelamento & desceu do caminhão e foi atropelado \\
\hline 22 & 117 & 66 & motorista & típico & atropelamento & estava trabalhando \\
\hline 23 & 118 & 22 & assaltante & típico & homicídio - arma de fogo & tiroteio com a polícia durante assalto \\
\hline 24 & 120 & 26 & assaltante & típico & homicídio - arma de fogo & tiroteio com a polícia \\
\hline 25 & 121 & 50 & guarda municipal & típico & homicídio - arma de fogo & $\begin{array}{l}\text { foi verificar um barulho durante } \\
\text { o trabalho }\end{array}$ \\
\hline 26 & 134 & 20 & prostituição & típico & homicídio - arma de fogo & $\begin{array}{l}\text { briga com pm durante batida } \\
\text { policial em bar }\end{array}$ \\
\hline 27 & 152 & 61 & motorista de ônibus & típico & $\begin{array}{l}\text { assalto seguido de morte - } \\
\text { arma de fogo }\end{array}$ & ônibus foi assaltado \\
\hline 28 & 158 & 22 & assaltante & típico & homicídio - arma de fogo & morto durante assalto \\
\hline 29 & 164 & 29 & policial civil & típico & homicídio - arma de fogo & durante batida policial \\
\hline 30 & 175 & 42 & mecânico & típico & colisão & testava veículo \\
\hline 31 & 180 & 24 & motorista municipal & trajeto & colisão & retornando do trabalho \\
\hline
\end{tabular}


miliares identificam esta relação. Seis (1/3) possuíam carteira de trabalho assinada - foram os casos de números 36, 95, 96, 105, 114 e 152. Do total, apenas $16 \%$ apresentaram renda mensal superior a 2 salários mínimos, e igual percentual mantinha jornada de trabalho semanal dentro das 44 horas determinadas constitucionalmente (aproximadamente 1/5).

As principais causas de morte destes 31 trabalhadores foram homicídio ( 15 casos por arma de fogo e 3 com arma branca), seguido de acidentes de trânsito ( 5 colisões e 4 atropelamentos). Os outros 4 casos foram esmagamento por máquina, choque elétrico, carbonização e afogamento.

Beraldo et al. (1993) observaram que $76,6 \%$ dos óbitos entre trabalhadores atingem pessoas na faixa entre 20 e 39 anos; quanto ao gênero, 96,3\% são de homens, o que chega a uma relação homem/mulher de $26 / 1$. Nesta pesquisa, 22 dentre os 31 casos (71\%) tinham até 39 anos e todos eram do sexo masculino. Esta ausência absoluta do sexo feminino pode ser em parte explicada pelo fato de essas causas de mortes estarem relacionadas às atividades lícitas e ilícitas desenvolvidas na rua (ou fora do estabelecimento fabril, comercial ou de serviços); são atividades laborativas socialmente determinadas que envolvem mais freqüentemente (ou quase que exclusivamente) o sexo masculino. Além disso, aspectos culturais e de gênero também podem ter influenciado a distribuição destas mortes.

As pessoas que morreram durante atividades relacionadas com o trabalho estavam ligadas à construção civil (7 casos), ao transporte (6), ao serviço de segurança (4), a serviços de mecânica (2), ao comércio (2), a outros serviços em geral (3), uma delas tendo atividade ignorada. Foram identificados 6 casos de mortes de pessoas durante a execução de atividades ilícitas, como assalto (3), receptação e tráfico de drogas e prostituição (1).

Estes dados confirmam os já encontrados por Beraldo et al. (1993), de 14,7\% dos óbitos serem de condutores de veículos automotores, $13 \%$ de trabalhadores braçais e $10,5 \%$ pessoas com ocupações não específicas. As duas ocupações mais atingidas na região norte foram a dos trabalhadores braçais e da agropecuária; na região centro-oeste, a da agropecuária e a dos condutores de veículos. Segundo este mesmo pesquisador, excluídos os acidentes não especificados, os de trânsito são a principal causa de óbitos por acidente de trabalho, com $34,8 \%$.

Neste estudo, os 16 casos ocorridos no local e no horário de trabalho, no exercício da fun- ção ou atividade de trabalho usual do acidentado, foram considerados Acidentes de Trabalho Típicos. Os 12 casos ocorridos no trajeto de casa para o trabalho, do trabalho para o local de alimentação, e vice-versa, foram enquadrados como Acidentes de Trajeto. Três casos foram classificados como Outros: um em que o homicídio não foi no local onde o jovem fazia a receptação, mas estava ligado à atividade; outro no qual o homicídio não foi na oficina mecânica onde era exercida a atividade, mas relacionava-se com a cobrança de honorários pelos serviços prestados pelo trabalhador; e um terceiro em que o agente policial se encontrava em um estacionamento, fora do horário de trabalho, mas foi morto por um grupo de delinqüentes com os quais já se havia confrontado (Tabela 3).

Um caso que necessita esclarecimento é o de um acidente de trajeto referente a um homem de 26 anos que estudava em faculdade privada durante o dia e trabalhava durante a noite. A família declarou desconhecer o que fazia e onde trabalhava, mas informou que com a remuneração deste trabalho ele pagava os próprios estudos, fazia a manutenção de seu carro novo e auxiliava a família. Faleceu à noite, em uma colisão no trajeto para casa, acompanhado por um homem cuja identidade a família desconhecia. Neste caso não foi possível identificar objetivamente a atividade desenvolvida, daí o enquadramento como Ignorada.

Outros casos próximos do objeto da pesquisa não foram classificados como relacionados com o trabalho pelos critérios previamente estabelecidos. Foi o que se deu com um suicídio por enforcamento, ocorrido no local de trabalho. Tratava-se de um pintor de paredes, de 26 anos, que trabalhava por empreitada. Não foram realizados exames toxicológicos que pudessem estabelecer relação entre o quadro psíquico que levou ao suicídio e a possibilidade de ação tóxica dos componentes das tintas ou solventes que utilizava; nem tampouco foi possível estudar as condições de ventilação e arejamento do local de trabalho. Houve também o caso de um comerciante de 51 anos que se suicidou com arma de fogo, a família havendo mencionado que ele "ia mal nos negócios", e que este teria sido "um dos motivos do suicídio". E ainda o de um desempregado de 23 anos que fazia biscates e morreu assassinado por arma de fogo. Embora um dos familiares tenha afirmado que o rapaz vinha cometendo pequenos furtos, não foi possível vincular objetivamente este homicídio com a atividade de sua manutenção, ou a de sua família. E por fim o caso de uma mulher de 37 anos, auxiliar de en- 
fermagem, vítima de um acidente de trânsito com moto. Estava afastada do trabalho por motivo de doença e se dirigia a uma perícia médica. O motivo do afastamento não foi relacionado com o trabalho (doença ou acidente), daí não ser enquadrável nos critérios de inclusão.

Os dados oficiais excluem os casos de acidente de trabalho referentes aos funcionários públicos civis e militares das três esferas de governo, bem como aos trabalhadores autônomos, domésticos, profissionais liberais, dirigentes e proprietários de micro, pequena, média e grande empresa. Todos mantêm vínculo previdenciário, inclusive com contribuições compulsórias, mas não possuem cobertura do seguro acidentário.

O Instituto Nacional de Seguro Social (INSS), órgão da Previdência Social encarregado de receber as notificações de acidentes de trabalho que atingem trabalhadores empregados urbanos e rurais, registrou 22 óbitos por acidentes do trabalho no ano de 1992, e, no mesmo período da pesquisa, de abril de 1992 a março de 1993, foram registrados 28 casos (INSS, 1995). Podemos inferir que os dados disponíveis em nosso meio referentes à morte no trabalho não traduzem a realidade dos óbitos por acidentes relacionados com o trabalho. Como já foi mencionado, foram identificados 31 óbitos, $17,71 \%$ de uma amostra de 175 casos que, por sua vez, correspondem a aproximadamente 1/5 (19,35\%) do universo da pesquisa. Com um total de óbitos por causas externas de 877, e caso essa amostra estudada possa representar todos estes óbitos, é muito provável que em Porto Alegre, no ano de 1992, tenham ocorrido aproximadamente 155 mortes relacionadas com o trabalho. Os dados divulgados pela previdência social referem-se apenas a 28 casos no mesmo período ( $1 / 5$ ou $18,06 \%$ do esperado).

Por outro lado, dos 31 casos identificados neste estudo, apenas 6 (também 1/5) eram pessoas que tinham carteira de trabalho assinada, podendo, pela legislação previdenciária vigente, ser classificados como acidentes do trabalho. Outros 5 casos ocorreram com trabalhadores autônomos, e 6 com funcionários públicos, sem vínculo de trabalho celetista (Tabela 4). Estes 11, embora do mercado de trabalho formal, não são elegíveis pelos critérios previdenciários, o que os mantêm "à margem" das estatísticas oficiais, contribuindo para o mascaramento dos números totais e reais. Podemos supor que o INSS, neste mesmo período e segundo seus critérios legais, provavelmente está dando cobertura aos casos que a legislação determina.

Tabela 3

Mortes relacionadas com o trabalho, segundo o tipo de inserção e atividades desenvolvidas no mercado de trabalho, Porto Alegre, 1992.

\begin{tabular}{lcccc}
\hline causa externa & at típico & at trajeto & outro & total \\
\hline homicídio & 7 & 4 & 3 & 14 \\
assalto com morte & 3 & 1 & - & 4 \\
atropelamento e colisão & 3 & 6 & - & 9 \\
outros & 3 & 1 & - & 4 \\
total & 16 & 12 & 3 & 31 \\
\hline
\end{tabular}

at: acidente de trabalho.

Tabela 4

Óbitos* relacionados com o trabalho, segundo o tipo de inserção do trabalhador no mercado de trabalho, Porto Alegre, 1992.

\begin{tabular}{lc}
\hline Tipo de Inserção & $\mathbf{n}$ \\
\hline Setor formal & 6 \\
Assalariados & 4 \\
$\quad$ Com carteira assinada (pedreiros - 2, motoristas - 2, carpinteiro - 1 e balconista - 1) & 6 \\
$\quad$ Sem carteira assinada (pedreiros - 2, serralheiro - 1 e servente - 1) & 5 \\
Funcionário público (policiais civis - 2, guarda municipal - 1, militar - 1, motorista - 1 e gari - 1) & 3 \\
Autônomos (motoristas - 3, representante comercial - 1, e corretor de imóveis - 1) & 6 \\
Atividade ilícita (assaltantes - 3, receptador - 1, traficante de drogas - 1, prostituição - 1) & 30 \\
Total
\end{tabular}

* Exclui uma morte por atividade ignorada. 
Além destes trabalhadores, existe outra grande parcela da População Economicamente Ativa que compõe o chamado mercado informal de trabalho, que trabalha e que também está excluída da atenção do Estado. Identificamos 7 casos com esta inserção no mercado de trabalho - 4 com assalariados sem vínculo formal de emprego e 3 entre pessoas que exerciam atividades por conta própria, mas sem a documentação legal (alvará de localização da prefeitura ou pagamento à previdência social como autônomo, por exemplo).

Os óbitos por causas externas relacionados com o trabalho atingiram mais freqüentemente trabalhadores jovens (entre 20 e 30 anos de idade), do sexo masculino, com pouca escolaridade, que trabalhavam em sobre-jornada sem vínculo empregatício reconhecido, e que, mesmo quando exerciam suas atividades no mercado de trabalho formal, faziam-no sem cobertura do seguro acidentário, e fundamentalmente em situações relacionadas com a violência urbana.

O típico acidente relacionado com o trabalho que provocou o óbito de trabalhadores residentes em Porto Alegre no ano de 1992 foi o homicídio por arma de fogo. Constatamos que os familiares e amigos, ao serem questionados sobre as condições em que ocorreu o acidente e o óbito, não os relacionavam com o trabalho, e, quando o faziam, conformavam-se com a situação, preferindo não procurar "seus direitos", quer no âmbito da Previdência Social, quer no direito civil ou penal. Em vários casos houve referência ao medo de represálias e perseguições por parte do "tomador" de serviços ou empregador. Além do medo referido, podemos acrescentar a descrença em fazer valer seus direitos junto às instituições públicas.

Quanto às informações das D.O.'s de Porto Alegre, podem ser classificadas como de boa qualidade. Todas foram preenchidas por peritos do Instituto Médico Legal (IML). No país, a região com maior percentual de D.O.'s de causas externas preenchidas pelo IML é a região Sudeste $(70,3 \%)$ e a com menor percentual é a Centro Oeste $(27,8 \%)$, sendo a média nacional de $57,4 \%$ (Beraldo et al., 1993).

As cópias destes documentos nos foram encaminhadas após classificação dos técnicos da SSMA/RS. O endereço domiciliar foi o item que mais freqüentemente não correspondeu à realidade. Tanto na D.O. como no IML, este dado era insuficiente. Os cemitérios e as funerárias demonstraram ser as melhores fontes na busca de endereços. Esta fidedignidade pode ser explicada pelo interesse econômico destas partes em encontrar os familiares para cobrir despesas com funerais e com a renovação do uso do túmulo. Por outro lado, a precariedade do preenchimento deste dado pode ser explicada pelo desconhecimento de sua importância.

Ainda quanto à qualidade das informações contidas na D.O. de Porto Alegre, dos 183 óbitos informados, apenas 7 apresentaram erro de enquadramento quanto ao domicílio do falecido. Tais D.O.'s estavam mal preenchidas, sem rua ou sem bairro, e com o nome da cidade constando sempre como Porto Alegre. Em um único caso não se confirmou o diagnóstico da causa básica da morte como causa externa. $\mathrm{Na}$ D.O. constava o diagnóstico de infecção generalizada em conseqüência de lesões provocadas por acidentes, e no decorrer da investigação este quadro não foi associado como provocado ou advindo de uma causa externa. Estes casos foram reencaminhados para a SSMA/RS para confirmação da análise e o necessário reenquadramento. Vê-se que o erro no diagnóstico da causa básica foi de 5,4 x 10-3, ou aproximadamente $5 / 1000$ casos.

Outro campo da D.O. que chama a atenção é o de número 38, onde deve estar especificado se o evento ocorreu por acidente de trabalho. Somente em dois casos estava preenchido, e ainda assim com classificação de ignorado; e em todas as demais 29 D.O.'s estava em branco. Questionamos o porquê deste fato, já que todos os casos tinham sido necropsiados e havia o diagnóstico da causa da morte. Os dados fornecidos pelo perito têm implicações judiciais imediatas. As circunstâncias em que ocorreu o evento, se a lesão foi por homicídio, suicídio, ou acidente de trabalho, por exemplo, ficam difíceis de ser explicitadas afirmativamente a partir do exame cadavérico, e tal exatidão é alcançada com o somatório de outras informações advindas de outras perícias (do local da ocorrência, de exames toxicológicos, da Criminalística, entre outras), do Inquérito Policial, e só podem ser concluídas com uma sentença judicial.

Como o desejável é que seja elevado o número de D.O.'s preenchidas por médicos, e como nas causas externas exige-se necropsia legal, a tendência é de incremento da utilização dos Institutos de Medicina Legal. Isto nos leva a supor uma diminuição da utilização do campo 38. Este fato é de grande relevância para a implementação do sistema de informações do setor saúde e, mais especificamente, em Saúde do Trabalhador, onde o campo 38 da D.O. vem sendo mencionado como importante instrumento. Porém, no presente estudo, esta fonte não se configurou como viável. 
Seis pessoas morreram exercendo atividades que podemos chamar de ilícitas, isto sem considerar o caso designado como de atividade ignorada, e igual número, 6 casos, foi de trabalhadores com Carteira do Trabalho assinada. Dada a magnitude do fenômeno constatado, podemos inferir que em Porto Alegre, para cada cidadão que morre em um acidente de trabalho formalmente enquadrável pela legislação previdenciária, outro morre exercendo uma atividade ilícita. É um dado bastante significativo para não ser considerado pelos setores competentes.

Entendemos que isto pode parecer estranho para parcela significativa dos estudiosos do campo do trabalho. O objetivo foi procurar chegar o mais próximo possível da realidade. Preocupar-se com a prevenção da morte precoce que o trabalho pode provocar, bem como com a promoção da saúde, exige desvendar os meandros desta realidade. Quanto da atividade de alguns, ou de todos estes cidadãos, não seria enquadrado realmente como trabalho, não fossem estas atividades ilícitas ou socialmente condenáveis? Como exemplo desta mobilidade conceitual, temos, nos dias de hoje, o comércio e o consumo de bebida alcoólica nos países de cultura islâmica, no sentido da penalização, e o uso pessoal de algumas drogas em certos países europeus, no sentido da descriminalização de muitas das atividades humanas aqui descritas como ilícitas.

Outro aspecto a considerar é que morreram 9/31 seja em atividades ilícitas (6/31), seja em ações de repressão e controle a estas atividades (3/31) - a morte do militar não se enquadra aqui. Nesta relação entre Acidente de Trabalho e Violência existe um duplo efeito. Se por um lado o trabalhador está morrendo na rua, e grupo significativo morre no exercício de atividades ilícitas, outra parcela não menos significativa das mortes, de 4/31 ocorreu com quem exercia atividade em organizações de segurança. Se considerarmos apenas o mercado formal de trabalho, essa relação sobe para 4/17 casos, o que, em outra palavras, quer dizer que entre os 17 óbitos ocorridos entre trabalhadores do mercado formal, 1/4 atingiu pessoas vinculadas aos órgãos de vigilância, controle e segurança.

A violência, como instrumento do poder para manter a ordem, fica claramente desvelada nesta pesquisa. Como sinônimo de dominação, e, em seu sentido jurídico, de constrangimento físico ou moral, mediante o uso da força ou da coação. Violência do Estado que expõe seus servidores a agressões ocupacionais típicas. Se para 6/31 casos enquadráveis pelo INSS foram identificados outros $4 / 31$ entre as forças de segurança do Estado, podemos depreender a grandeza do fenômeno na esfera policial. Estabelecendo-se comparações especificamente dentro da função pública, dos 6 óbitos ocorridos dentro deste setor, 4 foram de membros de suas forças de segurança e de repressão.

Em uma sociedade onde aumenta a flexibilização e a desregulamentação das condições de trabalho, é esperado o aumento do mercado informal. É cada vez maior o número de pessoas que encontram sua subsistência e de suas famílias em ocupações menos estáveis. Muitos dos familiares mencionaram que no início os trabalhadores achavam que "o bico" era transitório, que logo "acharia um emprego certo", mas, ao longo do tempo, esta situação, que parecia transitória, tornava-se permanente.

Grande parcela dos trabalhadores que estão morrendo no exercício do trabalho não estão sendo atendidos pelos programas prevencionistas do Estado. Os órgãos federais do Ministério do Trabalho (Inspeção Federal do Trabalho e Fundacentro) desenvolvem ações voltadas principalmente para os trabalhadores da indústria, do comércio e do meio rural, todos em atividades formais, regulamentares. Hoje, toda a regulamentação específica do Ministério do Trabalho deixa transparecer a adesão à teoria do risco profissional. Está centrada na participação e na atuação, por parte das empresas, na criação e no dimensionamento de serviços de medicina do trabalho e de engenharia de segurança, de comissões de prevenção de acidentes do trabalho, e em uma fiscalização cuja base jurídico-institucional é a da configuração do vínculo de emprego regido pelas leis trabalhistas (Machado \& Minayo, 1995). Toda a normatização da Portaria 3214/78, das Normas Regulamentadoras e de suas modificações posteriores baseiam-se na existência do vínculo empregatício e são dirigidas às empresas e empregados, excluindo, portanto, aproximadamente $5 / 6$ dos eventos relacionados com o trabalho que levaram à morte os trabalhadores de Porto Alegre em 1992.

Os serviços de saúde municipais e estaduais de nosso meio também estão voltados para o mesmo segmento de atividades, o que torna imprescindível o aprofundamento de estudos referentes às ocupações, objetivando redirecionar as ações do Estado para situações de risco. A concentração de serviços organizados e tradicionais nos setores vinculados à indústria fabril e da construção civil privilegiam um tipo de ação preventiva por parte da sociedade que certamente não está direcionada pa- 
ra contemplar estas novas exigências do mundo contemporâneo, do mundo do trabalho real.

\section{Conclusões}

Este trabalho apresenta os resultados de pesquisa epidemiológica de caráter prospectivo com base populacional, que identificou que apenas 1/5 dos óbitos relacionados com o trabalho são notificados como tais. A análise liga esse fenômeno às decisões de caráter legislativo e governamental que excluem a maior parte dos eventos Acidente de Trabalho com óbito da cobertura dos órgãos competentes do Estado, indicando a necessidade urgente de se reorganizarem os instrumentos de coleta de dados relacionados à saúde e ao trabalho.

Do ponto de vista das condições de defesa dos interesses dos trabalhadores, o segmento mais atingido pela morte no trabalho é aquele desassistido pelo Estado, através de suas políticas públicas de prevenção e assistência ao acidentado, e também pelos sindicatos e movimentos sociais. Parcela significativa da sociedade tem dificuldade para enquadrar como trabalho muitas das atividades aqui descritas.

Fica também claramente identificado que o que está levando estes trabalhadores ao óbito em situações relacionadas com o trabalho é a violência urbana. Classificam-se assim as 27/31 mortes que ocorreram por homicídio e por acidente de trânsito, relacionadas com arma de fogo, colisões, atropelamentos e armas brancas (facas, facões).

\section{Recomendações}

Quanto à prevenção na ocorrência destes eventos, a solução não está restrita às ações dos setores saúde e trabalho, mas implica ne- cessariamente a adoção de uma política de segurança pública, de segurança no trânsito, de articulação com o judiciário, incluindo, necessariamente, a educação. Implica ainda a implementação de políticas de emprego, de moradia, de transporte e de redistribuição de renda, entre outras.

Este é o desafio atual: a implantação de ações que contemplem as reais condições em que estes óbitos são gerados. $\mathrm{O}$ acidente de trabalho deve ser considerado dentro de sua real magnitude e transcendência. Para uma atuação consistente, será necessária a reconceitualização e a elaboração de teorias no âmbito da Saúde Pública (Machado \& Minayo, 1995). Esta revisão de teorias e de práticas deve acompanhar as mudanças que estão ocorrendo no mundo do trabalho, nas relações de trabalho e nas suas formas de organização, que caracterizam este final de século.

Pode-se concluir que, para fins de notificação epidemiológica e para fins de Vigilância em Saúde, é necessária a urgente revisão do conceito de óbito por acidente de trabalho, de modo a incluir todas as situações de risco oriundas do trabalho. Sem dimensionamento e diagnóstico da situação, não pode haver o adequado planejamento e a programação de ações que contemplem as reais necessidades sociais existentes.

As pessoas desenvolvem diferentes tipos de atividades buscando prover suas necessidades econômicas e de sobrevivência. Buscar formas alternativas de trabalho faz parte de nossa realidade social. Isto exige, portanto, que sejam repensados os mecanismos de diagnóstico, buscando-se valorizar as diferentes formas de inserção no mercado de trabalho, incluindo o mercado formal desassistido pelo seguro acidente de trabalho e o mercado informal, sob seus diferentes nexos, significados e dimensões. 


\section{Referências}

ALBORNOZ, S., 1994. O Que é Trabalho? São Paulo: Ed. Brasiliense, Coleção Primeiros Passos, no 171, $6 \underline{a}$ ed.

ALVES, S. \& LUCHESI, G., 1992. Acidentes do trabalho e doenças profissionais no Brasil: a precariedade das informações. Informe do SUS, 1:5-19.

ANTONIAZZI, R. G., 1992. Levantamento Epidemiológico de Acidentes de Trabalho em Hospital Geral de Porto Alegre. Monografia de Conclusão de Curso de Especialização, Porto Alegre: Centro de Documentação, Pesquisa e Formação em Saúde e Trabalho, Universidade Federal do Rio Grande do Sul.

BENDT, D. A., 1989. The psycological autopsy methodological considerations for the study of adolescent suicide. Journal of the American Academy of Child and Adolescent Psychiatry, 27:362366.

BENGUIGUI, Y., 1986. Investigação domiciliar na detectação de fatos de risco em infecções respiratórias agudas. I Congresso Brasileiro de Saúde Coletiva, Rio de Janeiro: Abrasco.

BERALDO, P. S. S.; MEDINA, M. G.; BORBA, E. A. \& SILVA, L. P., 1993. Mortalidade por acidentes do trabalho no Brasil - uma análise das declarações de óbito, 1979-1988. Informe Epidemiológico do SUS, 2:41-54.

CARVALHO, H. V. \& SEGRE, M., 1977. Medicina Social e do Trabalho. São Paulo: McGraw-Hill.

CHANDRAMOHAN, D., MHUDE, G. H., RODRIGUES, L. C. \& HAYER, R. J, 1994. Verbal autopsies for adult deaths: issues in their development and validation. International Journal of Epidemiology, 23:213-222.

CHATKIN, J. M.; MENDES, J. M.; DALCOMO, M. P.; PENNA, M. L. F. RIBEIRO, S. N. \& GERHARDT FILHO, G., 1990. Estudo de óbitos infantis por infecção respiratória aguda (IRA) por meio de inquérito familiar. Jornal de Pneumologia, 16:67-70.

FNS (Fundação Nacional de Saúde), 1994. Estatísticas de Mortalidade - Brasil 1989. Brasília: FNS

INSS (Instituto Nacional de Seguro Social), 1995. Ofício INSS no 803/95, Superintendência Estadual do Rio Grande do Sul. Porto Alegre: INSS.

LAURENTI, R. \& MELLO JORGE, M. P., 1993. O Atestado de óbito. São Paulo: Centro Brasileiro de Classificação de Doenças, MS/OPAS/OMS.

LITMAN, R. E., 1989. 500 Psycological Autopsies. Journal of Forensie Sciences, 34:638-646.
LOUREIRO, S., 1990. Brasil: desigualdade social, doença e morte. Congresso Brasileiro de Epidemiologia, Campinas: Abrasco.

MS (Ministério da Saúde), 1985. Manual para o Preenchimento da Declaração de óbito. Normas e Manuais Técnicos. Brasília: Centro de Documentação.

MACHADO, J. M. H. \& MINAYO GOMEZ, C., 1995. Acidentes de Trabalho: Concepções e Dados. In:. Os Muitos Brasis: Saúde e População na Década de Oitenta. (M. C. S. Minayo, org.), pp. 117-142. São Paulo-Rio de Janeiro: Editora Hucitec-Abrasco.

MARQUES, M. J. F., 1993. Características da Notificação de Acidentes de Trabalho em uma Fábrica da Grande Porto Alegre. Monografia de Conclusão de Curso de Especialização em Medicina do Trabalho, Porto Alegre: Centro de Documentação, Pesquisa e Formação em Saúde e Trabalho, Universidade Federal do Rio Grande do Sul.

NIS (Núcleo de Informações em Saúde), 1994. Estatísticas de Saúde: Mortalidade 1992. Volume 18. Por to Alegre: Secretaria de Saúde e Meio Ambiente do Rio Grande do Sul.

NIS (Núcleo de Informações em Saúde), 1995a. Estatísticas de Saúde: Mortalidade 1993. Volume 19. Porto Alegre: Secretaria de Saúde e Meio Ambiente do Rio Grande do Sul.

NIS (Núcleo de Informações em Saúde), 1995b. Informe Estatístico. Porto Alegre: Secretaria de Saúde do Rio Grande do Sul.

OMS (Organização Mundial de Saúde), 1985. Classificação Internacional de Doenças. 9a. revisão, 1975 São Paulo: Centro Brasileiro de Classificação de Doenças.

OPS (Organización Panamericana de la Salud), 1994. Las Condiciones de Salud en las Américas. Edición 1994, Volumen I. Washington: Organización Panamericana de la Salud.

POSSAS, C. A., 1981. Saúde e Trabalho: Crise da Previdência Social. Rio de Janeiro: Graal.

REGO, M. A. V., 1993. Acidentes e doenças do trabalho no Estado da Bahia. Informe Epidemiológico do SUS, 2:25-39.

RIBEIRO, H. P. \& LACAZ, F. A. C., 1984. De que Adoecem e Morrem os Trabalhadores. São Paulo: Amesp, Diesat.

ROUQUAYROL, M. Z.; BARBOSA, L. M. M.; ADERALDO, L. C. \& MOURA, L. G. X., 1993. Principais causas de mortes no Brasil, 1979-1988. Informe do SUS, 2:28-37. 